\title{
LEITURA DE TIRAS NAS AULAS DE LÍNGUA PORTUGUESA
}

\section{COMIC STRIPS READING IN PORTUGUESE LANGUAGE CLASSES}

\author{
Marcela Martins de Melo Fraguas"
}

Resumo: Neste estudo, explicitam-se as estratégias adotadas nas aulas de Língua Portuguesa para o desenvolvimento da competência leitora. O planejamento das atividades pautou-se na leitura do gênero tira, com alunos do nono ano do Ensino Fundamental. Entende-se que o estudante é um sujeito que constrói conhecimento, de forma gradual, na interação com o professor e com os colegas da turma. Para tanto, adotaram-se dois procedimentos: a participação guiada, explicitada por Solé (1998), e as autoexplicações, expostas por Abarca e Rico (2003). A pesquisa-ação (TRIPP, 2005) foi o método norteador da pesquisa em questão, visto, dentre outros aspectos, o planejamento da ação, com o objetivo de melhorar a prática de sala de aula. A percepção de que os estudantes traziam dificuldades na leitura de textos multimodais, de forma mais específica, das tiras, que, constantemente, apareciam nos materiais didáticos e nas avaliações, motivou a realização de atividades que os auxiliassem nesse sentido. Constatou-se, ao final, que os discentes conseguiram ler com maior desenvoltura e autonomia.

Palavras-chave: Ensino; Leitura; Tiras.

Aвstract: In this study, the strategies adopted in Portuguese Language classes for the development of reading competence are explained. The planning of activities was based on reading the comic strip genre, with students of the ninth grade of Elementary School. It is understood that the student is a subject who builds knowledge gradually, in the interaction with teacher and classmates. For that, two procedures were adopted: guided participation, explained by Solé (1998), and self-explanations, exposed by Abarca and Rico (2003). Action research (TRIPP, 2005) was the guiding method of the research in question, considering, among other aspects, action planning, with the objective of improving classroom practice. The perception that students brought difficulties in reading multimodal texts, in a more specific way, concerning comic strips, which constantly appeared in didactic materials and in evaluations, motivated

\footnotetext{
"Doutora em Letras pelo Programa de Pós-Graduação em Letras da Universidade do Estado do Rio de Janeiro (UERJ), área de concentração Estudos de Língua, linha de pesquisa Língua Portuguesa. E-mail: marcelammelo@yahoo.com.br.
} 
the achievement of activities that would help them in this sense. At the end, it was found that the students were able to read with greater ease and autonomy.

KeYwords: Teaching; Reading; Comic Strip.

\section{INTRODUÇÃo}

Na pesquisa em questão, apresentam-se os resultados das atividades com vistas ao desenvolvimento da competência de leitura, realizadas com alunos do nono ano do Ensino Fundamental, de uma escola da rede municipal de ensino, localizada no estado do Rio de Janeiro. O gênero tira foi escolhido pelo desejo de ensinar algumas estratégias apropriadas à leitura de textos multimodais, com vistas à produção de sentidos emanados pelos recursos verbal e não verbal, e, ainda, pela constatação das dificuldades dos alunos em relação à compreensão de textos desse gênero. Por vezes, os estudantes não realizavam as tarefas, alegando não terem compreendido o conteúdo das tiras lidas nas aulas.

A partir disso, organizei o planejamento das aulas de Língua Portuguesa, de modo a explicitar algumas das estratégias necessárias à leitura de textos do gênero tira. O método da pesquisa-ação norteou este estudo, considerando as quatro etapas de investigação-ação, expostas por Tripp (2005).

A organização das aulas teve por objetivo o desenvolvimento das seguintes competências e habilidades: a percepção da quebra de expectativa do leitor na leitura de textos de humor, o entendimento de que, em textos multimodais, o interlocutor não deve restringir a leitura ao conteúdo verbal, uma vez que a observação dos aspectos semióticos é essencial à compreensão, como as imagens (cenário, expressão facial dos personagens, etc.), o uso da pontuação, a distinção entre os balões de fala, de pensamento, de sussurro, de grito, entre outros, e, até mesmo, a existência do diálogo expresso pela ausência de fala dos personagens. Ao todo, foram realizadas quatro atividades de leitura e de produção de tiras: a) participação guiada, leitura em voz alta pela professora e contextualização das tiras junto à turma; b) leitura individual e verificação da compreensão leitora dos alunos por meio da autoexplicação; c) produção de tiras em grupo; e d) elaboração de falas em quadrinhos dados pela professora.

Neste recorte, apresentarei os resultados das atividades que contemplam os itens a e b, por se reportarem ao ensino-aprendizagem da leitura. Tais atividades ancoraram-se, principalmente, em dois aportes teóricos - a participação guiada, explicitada por Solé (1998) e as autoexplicações, segundo Abarca e Rico (2003).

Cabe destacar que o texto é entendido, conforme Marcuschi (2008, p. 72), como "um tecido estruturado, uma entidade significativa, uma entidade de comunicação e um artefato sócio-histórico". Haja vista que os textos se organizam nas mais diversas situações comunicativas 
sob a forma de gêneros, ensinar a ler implica considerar as especificidades dos gêneros selecionados no planejamento das aulas.

Consoante Guedes e Souza (1999), destaco que "ler é produzir sentido; ensinar a ler é contextualizar textos: o leitor atribui ao texto que tem diante de si o sentido que lhe é acessível" (GUEDES; SOUZA, 1999, p. 135); portanto, somente a apropriação do sistema linguístico não é suficiente para que o estudante compreenda determinados gêneros que circulam socialmente.

No momento da leitura, acionam-se o repertório cultural e linguístico dos estudantes; 0 texto, por sua vez, constitui prática dialógica desde o momento de sua elaboração, pois o autor é, também, seu primeiro leitor, não é, portanto, um emaranhado de elementos soltos, mas o resultado de um processo que envolve seleção e combinação, a fim de alcançar determinados objetivos em situações específicas. Desse modo, neste estudo, as aulas foram pensadas a fim de que os estudantes pudessem refletir acerca dessas escolhas. Visto a opção pelo gênero tira para o ensino da leitura, abordaram-se, nas aulas, outros aspectos, além dos linguísticos, essenciais à leitura de textos multimodais.

A tira é um gênero multimodal que soma os elementos verbais aos visuais (imagem, cor, balões, dentre outros). A leitura de textos multimodais levou à ampliação do conceito de letramento, visto o reconhecimento de que não só a escrita produz sentido nas práticas sociais. Com a internet, seu poder de alcance e sua influência, não se pode desconsiderar que grande parte dos alunos está acostumada a ler as imagens. A escola deve, portanto, ocupar-se dessa habilidade e transformá-la em matéria de ensino significativo, direcionando de forma apropriada tal leitura.

Com as estratégias de leitura, além de mostrar aos alunos que a produção monitorada, como o caso do texto para uma tarefa escolar, pressupõe um planejamento e seleção/escolha de recursos linguísticos e semióticos, chamo a atenção para o fato de que todo leitor habilidoso, ainda que de forma inconsciente, adota certos procedimentos que auxiliam a compreensão do texto, faz previsões, observa o título, subtítulo, imagens, disposição gráfica, busca o sentido das palavras desconhecidas, relê, lê em voz alta, resume etc., de modo a refletir sobre a tarefa realizada.

\section{CONSIDERAÇÕES SOBRE O GÊNERO TIRA}

Segundo Ramos (2017), a tira é um gênero autônomo dentro do hipergênero quadrinhos. Não raro, em questões que figuram em materiais didáticos, provas diagnósticas e de vestibulares, as histórias em quadrinhos se resumem a um único gênero, dadas as marcas comuns que compartilham, como balões, onomatopeias, quadrinhos, tendência de composição de histórias em narrativas e outros. 
Os pressupostos de hipergênero, a que se refere o estudioso, elaboraram-se a partir da tensão que perpassa as características de estabilidade do gênero, já anunciada por Bakhtin (2011, p. 262) ao determinar os gêneros do discurso como tipos relativamente estáveis de enunciados. Ainda que se considerem características comuns a alguns gêneros, estas não são rígidas.

Com base na constatação da variedade dos gêneros e na infinidade de termos de que dispõe o locutor para categorizá-los, Maingueneau (2013) aponta que a categorização se apoia em critérios bastante heterogêneos, que variam em função do uso que se faz delas: "as categorias de que dispõe um leitor que procura um livro em uma livraria não são as dos livreiros, as dos críticos literários dos jornais, nem as dos teóricos de literatura" (MAINGUENEAU, 2013, p. 65).

Pautando-se, principalmente, nos gêneros instituídos, os que, em sua visão, aproximam-se das situações mais convencionais, o estudioso expõe o conceito de etiquetas. ${ }^{1}$ É com base em tal conceito que Ramos (2009) define, como já exposto, o gênero tira como autônomo dentro do hipergênero quadrinhos. Segundo Maingueneau (2013), as etiquetas atribuem-se aos textos por seus produtores e orientam como serão recebidos socialmente, podendo se referir às propriedades formais do texto, à interpretação ou a ambos. O hipergênero é uma etiqueta que se relaciona ao modo de organização do texto e à sua formatação:

Trata-se de categorizações como "diálogo", "carta”, "ensaio", "diário", "carnê" etc., que, de algum modo, permitem formatar o texto, mas não dizem nada, ou dizem muito pouco, acerca de seu funcionamento preciso. Com efeito, o hipergênero não é, propriamente falando, um gênero do discurso, um dispositivo de comunicação historicamente definido, mas um tipo de organização textual de coerções pobres, relativamente estável com o decorrer dos séculos, no interior do qual podem-se desenvolver variadas encenações da palavra. O diálogo, que, no ocidente, permitiu etiquetar os mais diversos textos durante aproximadamente dois mil e quinhentos anos, é um bom exemplo de hipergênero: basta que duas pessoas conversem para que possamos falar de "diálogo". Do mesmo modo, basta que coloquemos uma data no começo de fragmentos de texto e que organizemos esses fragmentos em ordem cronológica para que possamos conferir ao conjunto assim formado o estatuto de "diário". O diálogo, assim como a carta ou o diário, podem acolher diversos mais conteúdos (MAINGUENEAU, 2013, p. 122).

Acerca das diferentes criações ligadas aos quadrinhos, Ramos (2009) analisa sua forma de produção, bem como seu funcionamento nas situações sociocomunicativas. Dentre as tendências encontradas, destacam-se duas: "predominância da sequência narrativa, representada em um ou mais quadros, e uso da linguagem gráfica das histórias (como os balóes)"

${ }^{1}$ Rótulos, na tradução de Ramos (2009). 
(RAMOS, 2009, p. 361-362). Para o autor, tais elementos antecipam informações genéricas ao leitor e orientam a leitura de textos que compartilham as mesmas características. Nesse sentido, estabelece que quadrinhos ou histórias em quadrinhos seriam uma etiqueta a abrigar gêneros com características comuns:

Um grande rótulo, denominado história em quadrinhos ou somente quadrinhos, une diferentes características comuns e engloba uma diversidade de gêneros afins. Rotulados de diferentes maneiras, utilizam a linguagem dos quadrinhos para compor um texto narrativo dentro de um contexto sociocomunicativo (RAMOS, 2009, p. 362).

Assim, segundo o estudioso, dentro do hipergênero quadrinhos, estão "os cartuns, as charges, as tiras cômicas, as tiras cômicas seriadas, as tiras seriadas e os vários modos de produção das histórias em quadrinhos" (RAMOS, 2009, p. 362).

No que diz respeito ao ensino de Língua Portuguesa, o autor expõe que há certa predileção pela leitura de tiras; possivelmente, pela densidade de conteúdo, já que são textos que reúnem bastante informação do ponto de vista linguístico, e pelo tamanho diminuto, um facilitador para a produção de material em larga escala.

Koch e Elias (2014) destacam a leitura com foco na interação autor-texto-leitor como uma atividade de produção de sentidos "que se realiza evidentemente com base nos elementos linguísticos presentes na superfície textual e na sua forma de organização, mas requer a mobilização de um vasto conjunto de saberes no interior do evento comunicativo" (KOCH; ELIAS, 2014, p. 11). Aos elementos linguísticos, acrescentam-se os elementos semióticos (imagens, cores, linhas cinéticas, expressões faciais, posição, ângulo etc.). Para a compreensão de uma tira, além disso, precisam ser ativados os conhecimentos prévios do leitor, o qual precisa ser levado a fazer inferências, a fim de perceber os aspectos não explícitos do texto.

Muitas vezes, há um uso improdutivo do gênero, quando as perguntas trazidas pelo material didático ou mesmo as elaboradas pelo professor priorizam o uso verbal, e o aluno constata que não precisa do visual, do não verbal, para responder às questões. Em situações desse tipo, seria melhor a escolha de outro, de modo que o estudante não pense que não precisa de uma visão global para atender às expectativas de resposta. A regularidade de tais atividades fará com que ele desenvolva uma leitura mecanizada, restrita aos aspectos verbais, não ampliando, pois, suas habilidades leitoras.

O mesmo acontece com tiras usadas sempre como pretexto para o ensino-aprendizagem de conhecimentos de natureza gramatical. Aqui, o pretexto não é visto como algo negativo em razão do entendimento de que pode ser um dos objetivos da leitura, como exposto por Geraldi (2011, p. 92). A problemática consiste em priorizar o uso de tiras como razão para trabalhar apenas normas gramaticais, desconsiderando todos os outros elementos que lhes 
são inerentes. Praticado dessa forma deficitária, o ensino não forma leitores nem produtores de texto autônomos.

Entre os fatores constitutivos dos processos de leitura, Koch e Elias (2014) entendem que alguns estão relacionados ao autor e ao leitor do texto, tais como bagagem cultural, conhecimento de mundo, contextos de produção e de recepção, e outros derivados do próprio texto, podendo ser de ordem material ou linguística. Os de natureza material dizem respeito ao tamanho e à clareza das letras, cor e textura do papel, comprimento das linhas, parágrafos longos, entre outros. Esses aspectos podem ser um impedimento à compreensão leitora, sobretudo na escola pública, pois nem sempre as cópias dos materiais didáticos e das provas são de boa qualidade. Por isso, o uso do livro didático seria um facilitador do trabalho com tiras, ainda que limite o poder de seleção acerca do material utilizado em sala de aula. O segundo fator, de natureza linguística, relaciona-se ao léxico, estruturas sintáticas, ausência de sinais de pontuação, por exemplo. Ao professor, cabe orientar o aluno no que concerne ao ensino-aprendizagem nesse sentido. No tocante ao trabalho com textos multimodais, a mediação deve ir além da aprendizagem dos elementos linguísticos, contemplando os recursos semióticos, conforme já exposto.

\section{A Leitura de tiRAS NA ESCOLA POR MEIO DA PARTicipaÇão GUiAda}

Esta pesquisa foi realizada com alunos do nono ano do Ensino Fundamental de uma escola da rede municipal de ensino, situada no estado do Rio de Janeiro. O método que norteou o estudo foi o da pesquisa-ação, como já destacado, que atendeu às quatro fases do ciclo básico da investigação-ação, expostas por Tripp (2005, p. 446): planejamento, ação, monitoramento e descrição dos efeitos da ação e avaliação dos resultados. Além de ser a professora da turma, assumi o papel de pesquisadora, a fim de problematizar não só o conhecimento produzido por meus alunos, mas também o conhecimento acerca do meu próprio fazer docente. Dadas as dificuldades apresentadas pelos estudantes em atividades de leitura de tiras, busquei estratégias nesse sentido, que lhes auxiliassem a mobilizar os conhecimentos necessários à leitura de textos multimodais, de forma mais específica, de tiras cômicas, frequentemente encontradas nas avaliações diagnósticas e nos materiais didáticos utilizados na escola.

Apresento, neste espaço, um recorte da pesquisa realizada. Para tanto, ancorei minha prática, principalmente, em dois procedimentos: a participação guiada do professor, explicitada por Solé (1998), com base em denominação de Rogoff (1984), e as autoexplicações, destacadas por Abarca e Rico (2003).

Acerca da participação guiada, Solé (1998) salienta se tratar de um processo de construção conjunta, exposto, em 1988, por Edwards e Mercer, no qual o professor, em um primeiro momento, deve ajudar o aluno a relacionar seu conhecimento prévio ao conhecimento necessário para abordar determinada situação educativa e 
em segundo lugar, o aluno dispõe desde o princípio - porque o professor lhe proporciona isso - de uma visão de conjunto ou estrutura geral para levar a cabo sua tarefa. São situações em que, como terceira característica, se permite que a criança assuma a responsabilidade em seu desenvolvimento de forma progressiva, até se mostrar competente na aplicação autônoma do que foi aprendido (SOLÉ, 1998, p. 76).

Koch e Elias (2009) destacam o papel do contexto na elaboração dos sentidos. O entendimento da leitura pode ser, dessa forma, menor ou maior, dependendo dos dados contextuais que são oferecidos ao leitor. Nas palavras das autoras,

em uma situação de interação, quando levamos em conta os interlocutores, os conhecimentos considerados como compartilhados, o propósito da comunicação, o lugar e o tempo em que nos encontramos, os papéis socialmente assumidos e os aspectos histórico-culturais, estamos atuando com base no contexto e em seus elementos constitutivos $(\mathrm{KOCH}$; ELIAS, 2009, p. 76).

Considerando os princípios da participação guiada, a leitura das tiras realizou-se em diálogo com os estudantes, de modo que juntos pudéssemos contextualizá-las. As primeiras leituras contaram com uma contextualização maior de minha parte, diminuída à medida que percebia que os estudantes ganhavam autonomia e elaboravam suas próprias inferências.

Descrevo, na sequência, as práticas de leitura realizadas a partir de três tiras - duas de Adão Iturrusgarai e uma de Mauricio de Sousa -, porém outras tiras, de outros autores, também foram lidas ao longo de todo planejamento.

Uma das principais queixas dos estudantes em relação à leitura de tiras é "que elas não têm graça". Tal resposta é dada diante da pergunta para explicar seus efeitos de humor. Contudo, na leitura de um texto em que seja necessária a mobilização de repertórios extralinguísticos e de conhecimentos linguísticos mais complexos, o discente exterioriza o seu não entendimento, dizendo não ter achado graça, na tentativa de se esquivar de responder a questão. Sobre a leitura de tiras cômicas, Ramos (2017) destaca que uma de suas principais características é a quebra de expectativas do leitor, provocada por todos os elementos verbais e não verbais que constroem o texto, tendo em vista que "elas trazem uma leitura específica que, se não desvendada pelo leitor, não leva ao sentido humorístico” (RAMOS, 2017, p. 79).

A dificuldade por parte dos discentes de acionar diferentes repertórios e de ler de maneira global foi constatada durante a leitura da seguinte tira de Adão Iturrusgarai: 
Figura 1 - Tira 1 de Adão Iturrusgarai

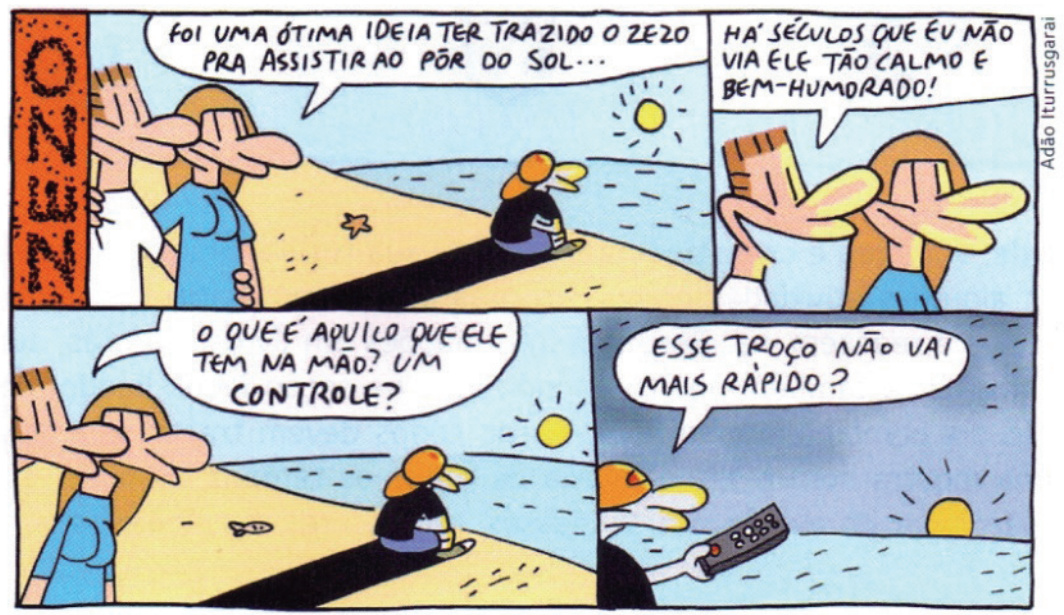

(Folha de S. Paulo, 18/6/2005.)

Fonte: ITURRUSGARAI, Adão. Disponível em: https://acervo.folha.com.br/leitor.do?numero=16476\& anchor $=5516011 \&$ origem $=$ busca\&pd $=81 \mathrm{cda} 85 \mathrm{c} 33 \mathrm{~d} 9 \mathrm{dec} 992 \mathrm{~b} 442 \mathrm{f5}$ e41251bb. Acesso em: 31 maio 2019 .

Em sua maioria, os estudantes não conseguiram fazer as conexões necessárias ao entendimento da Figura 1, que, para eles, não teve sentido. Alguns responderam que o humor não existia, visto a impossibilidade de "avançar" o Sol com um controle remoto. Esses alunos não associaram os elementos não verbais e verbais ao conhecimento extralinguístico.

Ao discorrerem a respeito dos processos envolvidos na leitura, Abarca e Rico (2003, p. 139) apontam que "quando há dificuldades de compreensão, a causa não deve ser buscada no leitor ou no texto em separado, mas na inadequação entre o texto e o leitor e, mais concretamente, no processo no qual se conjugam ambos os elementos, as inferências". O entendimento da tira de Iturrusgarai pressupõe a inferência de que os adolescentes estão tão ligados à tecnologia que não querem sair de casa para realizar outras atividades, por isso se tornam, na visão de seus pais, mal-humorados e estressados, motivos pelos quais Zezo foi levado para assistir ao pôr do sol.

Os autores salientam também que "algumas ideias textuais são evocadas e outras construídas durante a leitura” (2003, p. 142). Assim, aos interlocutores que acompanham o trabalho do cartunista e têm consciência de que o personagem Zezo representa o típico adolescente que "não gosta de nada", a leitura torna-se mais acessível. Essa seria uma inferência evocada, facilitadora da compreensão. Há, entretanto, o que os autores denominam de linhas contínuas, que não são frutos de inferências e que estão explícitas no texto, como, por exemplo, a quebra de expectativas evidenciada pelo uso do controle remoto, indicador de que Zezo quer "avançar" o Sol. Tal informação explícita leva o leitor a inferir que o menino não está relaxando e que deseja o fim daquele momento. No caso dessa tira, a leitura restrita às linhas contínuas impede a lógica com o mundo real, por isso o entendimento é comprometido. 
Tais apontamentos foram feitos por mim em relação à tira lida. Após essa intervenção, foi possível discutir com os alunos a necessidade de controle e a distinção entre as classes gramaticais da palavra implicando mudança de significado, a falta de interação com a natureza por conta do excesso de tecnologia - principalmente, o telefone celular, artefato mais utilizado pelos alunos - , a dificuldade de o ser humano "desacelerar" e o contexto tecnológico do ano (2005) em que a tira foi produzida, já que, atualmente, a TV não é mais tão atrativa como a internet. Os estudantes destacaram a possibilidade de uma releitura desse texto com os aparelhos tecnológicos utilizados por eles na atualidade, como, por exemplo, um controle de videogame, que possibilitaria ao personagem avançar a fase e ir para outro cenário ou até mesmo o uso de um editor de imagem, por meio de computador ou do próprio celular, com o qual seria possível apagar o Sol, de modo que o dia terminasse mais cedo. Tais apontamentos evidenciam que o contexto no qual a tira de Iturrusgarai foi elaborada já não é tão explícito aos educandos nos dias atuais, o que pode comprometer, de certa forma, sua compreensão.

A percepção das especificidades do gênero, do estilo do cartunista e, em especial, das características do personagem principal ampliou o repertório dos alunos, tornando a leitura de outras tiras de Iturrusgarai mais compreensíveis, visto que "quanto mais conhecimento tenha um leitor e melhores estratégias possua, menos penoso será o processo e melhor compreensão final se obterá" (ABARCA; RICO, 2003, p. 143).

Figura 2 - Tira 2 de Adão Iturrusgarai



(Folha de S. Paulo, 13/8/2005.)

Fonte: ITURRUSGARAI, Adão. Disponível em: https://acervo.folha.com.br/leitor.do?anchor=5465107 $\& p d=0 d c 0 a 76120 f 8 a 45 e b 79 b 870 f 4 f 425 c 8$ e. Acesso em: 23 jul. 2019.

Dessa forma, na leitura da segunda tira (cf. Figura 2), os estudantes conseguiram, considerando os elementos semióticos, perceber o sentido produzido pelo acréscimo da gravata ao traje do adolescente como forma de atender ao pedido de vestir-se adequadamente para um casamento. Atentaram, ainda, para a expressão facial dos pais, que, nos primeiros quadrinhos, parecem muito bravos e ficam perplexos no último. A atenção voltada exclusivamente para 
os elementos linguísticos não teria sido suficiente para o entendimento da narrativa, dado que, nos últimos quadrinhos, não há a presença da modalidade verbal escrita, contudo, ainda assim, a comunicação se estabelece.

Haja vista a participação guiada, mostrei-lhes que a ausência de falas dos personagens também produz significado no terceiro quadro, pois a imagem gera a expectativa de que $o$ menino reapareça formalmente vestido, o que não acontece; já no desfecho, ele "obedece" aos pais segundo seus próprios critérios, e, mais uma vez, a rebeldia inerente ao adolescente é destacada.

Além de textos de Iturrusgarai, foram lidas tiras de Mauricio de Sousa, criador dos quadrinhos da Turma da Mônica. Dentre elas, a Figura 3, exposta a seguir:

Figura 3 - Tira de Mauricio de Sousa
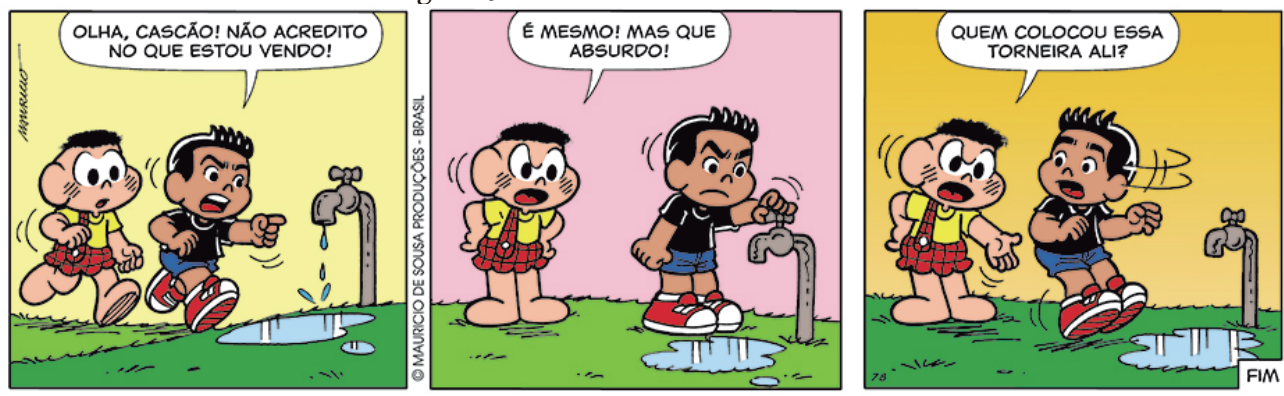

Fonte: SOUSA, Mauricio de. Disponível em: http://turmadamonica.uol.com.br/ tirinhasdomarcelinho/. Acesso em: 23 jul. 2019.

É essencial à compreensão dessa tira o conhecimento por parte do interlocutor de que a característica principal do Cascão, inclusive que dá origem ao seu nome, é o fato de não tomar banho. Sem tal informação, não explícita no texto, a quebra de expectativas não acontece, visto o não entendimento de que ele não está preocupado com o desperdício de água da mesma forma que Marcelinho, mas com a torneira e a possibilidade de se molhar, algo terrível para o Cascão.

O site da Turma Mônica, ${ }^{2}$ em parte destinada à descrição das personagens, revela que Marcelinho é extremamente correto. Embora tal dado não seja tão essencial à leitura quanto o que diz respeito a Cascão, é um elemento contextual que ajuda a entender a irritação do menino com a torneira aberta, destacada em suas expressões faciais nos dois primeiros quadrinhos. Interessante notar a mudança na face dos personagens ao longo da narrativa. Em relação ao elemento linguístico, a oração "Mas que absurdo!" assume, também, diferentes conotações para cada um dos personagens, bem como a última fala de Cascão, crucial para a quebra, pois revela que sua indignação é diferente da de Marcelinho.

${ }^{2}$ Disponível em: http://turmadamonica.uol.com.br/personagem/marcelinho/. Acesso em: 23 jul. 2019. 
Destaco a relevância da mediação durante a leitura das tiras nas aulas, considerando a seguinte reflexão: "é um direito de cidadania do aluno ter acesso aos meios expressivos construídos historicamente pelos falantes e escritores da língua portuguesa para se tornar capaz de ler e compreender todo e qualquer texto já escrito nessa língua” (GUEDES; SOUZA, 1999, p. 135). E, para que exerça tal direito, os educandos precisam interagir em todos os anos de escolaridade e em diferentes níveis de complexidade. Isso posto, não é demais dizer que "assim como, numa primeira instância, ensinar a ler é alfabetizar, levar o aluno ao domínio do código escrito, ensinar a ler continua sendo levar o aluno ao domínio de códigos mais elaborados e especializados" (GUEDES; SOUZA, 1999, p. 136).

É função da escola e dos professores ampliar os domínios de leitura dos educandos, de modo que enxerguem além da superfície textual, e esta não é uma tarefa restrita aos professores de Língua Portuguesa. A experiência da leitura das tiras nas turmas de nono ano, por meio da participação guiada, mostrou que, à medida que o repertório discente era ampliado, minhas interferências tornavam-se menores e muitos dos comentários necessários ao entendimento das tiras eram feitos pelos próprios estudantes.

\section{VERIFICAÇÃO DA COMPREENSÃO LEITORA POR MEIO DAS AUTOEXPLICAÇõES}

A fim de ajudar os leitores a elaborarem inferências, Abarca e Rico (2003) sugerem, como procedimento, as autoexplicações. Os pesquisadores adotaram o método com estudantes de 13-14 anos, apresentando-lhes um texto sobre o sistema circulatório humano e pedindo que explicassem o que cada frase significava, de modo a relacionar cada nova informação ao que tinham lido anteriormente (ABARCA; RICO, 2003, p. 151).

Utilizei tal estratégia em uma atividade realizada com os alunos do nono ano. Para tanto, entreguei-lhes uma folha com duas tiras (cf. Figuras 4 e 5), uma de Adão Iturrusgarai e outra de Dik Browne, criador do personagem Hagar, o Horrível, e uma pergunta direta: "o que você entende da tira?”. A intenção era a de analisar se realizariam satisfatoriamente, e com maior autonomia, a leitura solicitada, acionando os conhecimentos adquiridos nas aulas anteriores.

Ressaltei, ainda, que os estudantes não precisavam se identificar, visto não se tratar de uma tarefa cujo fim era a obtenção de nota, e, sim, o diagnóstico. Dos sessenta e quatro alunos que responderam à questão, apenas treze escreveram seus nomes. Embora as reflexões aqui apresentadas não incidam na quantificação, acredito que a consideração desse dado é relevante para a problematização de que os discentes sempre se sentem avaliados no espaço escolar e de que a leitura nesse contexto raramente é despretensiosa. 
Figura 4 - Tira 3 de Adão Iturrusgarai
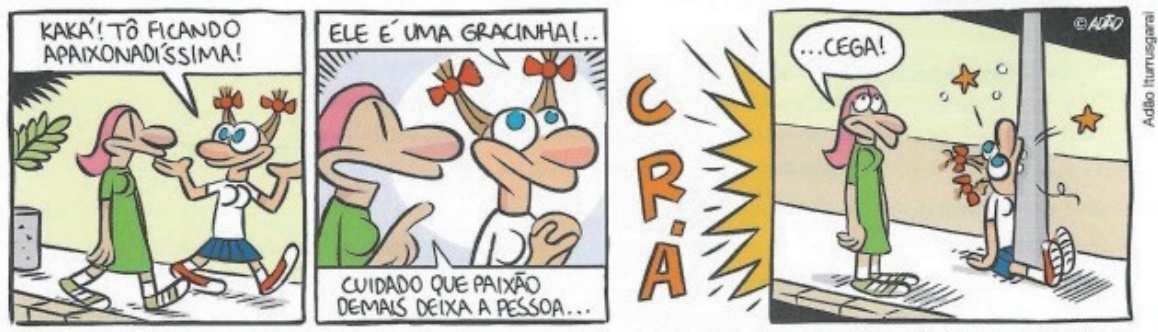

Adão Iturrusgarai. Kiki - A primeiro vez. São Paulo: Devir, 2002. p. 32.

Fonte: ITURRUSGARAI, Adão. Disponível em: https://brainly.com.br/tarefa/12465204. Acesso em: 31 jul. 2019.

Figura 5 - Tira de Dik Browne
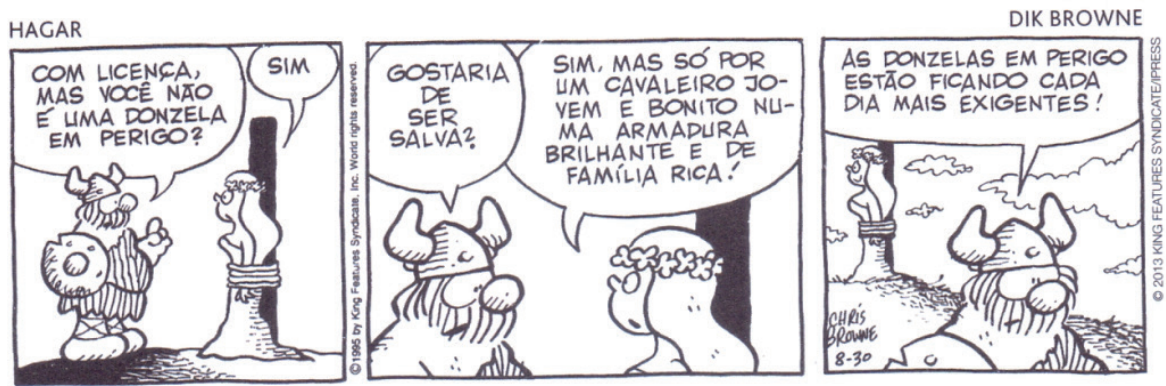

Fonte: BROWNE, Dik. Disponível em: http://mundoletras2009.blogspot.com/2018/11/prova-sobreadjetivos-e-pronomes.html. Acesso em: 31 jul. 2019.

A análise das respostas da tira da Figura 4 evidenciou que nenhum aluno deixou a atividade em branco, que as explicações dadas não estavam erradas, que alguns estudantes parafrasearam a narrativa e outros deram respostas incompletas. Para Abarca e Rico (2003, p. 152), há dois fatores que limitam as autoexplicações: o pouco conhecimento prévio dos leitores diante das inferências requeridas pelo texto e a leitura superficial, ambos geradores das paráfrases. Acerca da incompletude das respostas, creio que esta se dê mais pela falta de desenvoltura com a escrita do que pela não compreensão leitora. Há problemas estruturais de ortografia e de coesão, por exemplo, que configuram um entrave à expressão do pensamento no papel.

A tira de Iturrusgarai exige o entendimento de que a palavra cega foi empregada em sentido figurado, como expressão utilizada popularmente para dizer que quem se apaixona não vê defeitos na pessoa amada, e em sentido literal de não enxergar. Antes que Kaká pudesse completar a frase na primeira acepção, Aline, por distração, bate no poste, dando outro significado à palavra. O superlativo absoluto sintético no adjetivo apaixonada é uma linha contínua que leva à inferência de que só alguém muito apaixonado ficaria "cego", o mesmo acontece com o sufixo formador de diminutivo em gracinha, reforçando o encantamento da menina. 
As reticências, no segundo quadro, são propositais, visto que, além da interrupção da fala da personagem, geram o suspense para a cena inesperada no último quadro. Esse momento é antecipado pela onomatopeia "Crá", indicando que algo aconteceu e, por esse motivo, a fala de Kaká foi interrompida, ganhando nova significação. Mudam também as expressões faciais das personagens, que contribuem para o efeito de humor: Kaká surge, no último quadro, apática, e Aline com a cara no poste.

Pela análise das respostas, pude avaliar que os estudantes compreenderam o texto, uma vez que a maioria das explicações se aproximou dessa visão; entretanto, revelam também a dificuldade de escreverem suas conclusões a respeito da leitura. ${ }^{3}$ Eis alguns exemplos: "a menina está cega de amor, já que dizem que o amor é cego ou que cega as pessoas, então ela está cega de amor, ela não viu o poste"; "ela fica pensando muito nele que acaba ficando cega de amor e não ver o poste"; "eu entendo que a menina está apaixona e tanto fala não prestou atesão e bateu no poste em quato a Kaká falava que o amor deixa as pessoas segua"; "a menina ficou lerda porcausa da paixão e poriso deu de cara no poste"; "a personagem está tão apaixonada ao ponto de não enxergar os objetos na propria frente"; "eu entei que ela estava muito apaixonada ai ela ficou pensando no garoto ai ela se destraiu e batou com o rosto no poste".

Os desvios e os truncamentos nos escritos dos alunos saltam aos olhos e o primeiro impulso é o de corrigir todo o texto apenas sob o viés da forma. Foi preciso, contudo, alinhar quais habilidades se esperava trabalhar em cada atividade, a fim de que não desqualificasse o trabalho discente. Embora as barreiras com a língua ainda sejam muitas, do ponto de vista da leitura do gênero apresentado, destaco que os estudantes atenderam às expectativas, tendo em vista que, em avaliações e outras tarefas, costumavam deixar as perguntas em branco. $O$ fato de todos terem respondido é um indicativo de que se sentiram encorajados a ler o texto, pois conheciam as estratégias necessárias à sua leitura.

Na Figura 5, de Dik Browne, há uma sátira ao ideal de perfeição que aparece, geralmente, nos contos de fadas. A quebra de expectativas consiste no fato de a donzela se recusar a ser salva por Hagar por ele não atender ao padrão de beleza, de elegância, de status social e financeiro que ela deseja. O que poderia ser motivo de raiva é transformado em efeito de humor, quando o "problema", para o viking, está no alto nível de exigência da personagem, e não nele.

A observação das respostas revelou muitas paráfrases, como "a donzela não queria ser salva por ele e sim por um cavaleiro bonito e rico"; "um cavaleiro foi salvar a donzela só que ela queria um cara bonito, de familia rica, com uma armadura bonita então ele pegou e foi embora"; "eu entendi que a donzela em perigo só queria ser salva por um cavaleiro jovem e bonito num brilhante e de familia rica, e que ela estava ficando cada vez mais exigentes!”.

\footnotetext{
${ }^{3}$ Não foram transcritas todas as respostas dos estudantes por questões de espaço e também porque este trabalho apresenta, como foco, a problematização do ensino de língua enquanto prática, as atividades realizadas pelos alunos, e não a quantificação de resultados. Cabe ressaltar que as respostas foram reproduzidas da mesma forma que foram, pelos estudantes, escritas.
} 
Os estudantes também foram influenciados por suas opiniões pessoais sobre o tema, muitos chamaram a donzela de interesseira em suas respostas: "eu acho que ela e muito exigente"; "eu entendi que a donzela em perigo e uma intereceira ela do tipo armou aquilo pra ver se conseguia casar com um principe e mudar de vida"; "elas exigem muito do pouco. E por isso preferem ficar presa a espera do homem perfeito, porque pra elas é o certo".

Alguns alunos perceberam o sentido implícito: "que ela é muito exigente, e o homem ofereceu ajuda mais ele não era do estilo que ela queria. Aqui podemos ver o interesse"; "ela ñ queria ser salva por ele só porque ele não é um príncipe rico"; "eu entendi que ela queria ser salva por cavaleiro novo de armadura brilhante e de familha rica, não de um cavaleiro velho de armadura velha"; ela não estava esperando esse cara velho e gordo, estava esperando algo melhor"; "que a princesa queria o oposto do cavaleiro que foi salvar".

Comparando as explicações para cada uma das tiras, constato que houve mais dificuldade nas respostas da Figura 5. A isso, pode-se atribuir o fato de a compreensão desse texto depender mais dos aspectos verbais, das falas das personagens, do que dos não verbais e, talvez, para alguns, os problemas de leitura - principalmente, de decodificação - tenham sido um entrave. O entendimento da Figura 5, além disso, dependia do elemento contextual de que, em geral, nos contos de fadas, as donzelas ou princesas são salvas por um príncipe. Os alunos que não dispunham desse conhecimento demonstraram mais dificuldade para responder.

\section{CoNSIDERAÇões FINAIS}

Neste estudo, explicitei as estratégias para o desenvolvimento da competência leitora do gênero tira, adotadas com alunos do nono ano do Ensino Fundamental. Acredito que o trabalho com a linguagem em torno desse gênero textual seja bastante produtivo ao ensino, dado que, por as tiras serem multimodais, pressupõem que o leitor mobilize diferentes repertórios e estratégias para sua compreensão.

Ao longo de algumas aulas, li com as turmas diversos textos, produções de cartunistas brasileiros, tais como as de Adão Iturrusgarai e de Mauricio de Sousa, e traduções, de Bill Watterson, de Dik Browne, entre outros. Ancorada, principalmente, pelos estudos de Ramos (2009, 2017), Solé (1998), Koch e Elias (2009, 2014) e Abarca e Rico (2003) ensinei aos alunos algumas das estratégias apropriadas à compreensão do gênero multimodal. Para tanto, valendo-me da participação guiada, destaquei a associação das linguagens verbal e não verbal como produtoras de sentido, bem como a importância dos conhecimentos linguísticos, o uso da pontuação, e extralinguísticos, os conhecimentos prévios, dentre outros. À medida que os alunos adquiriam novos repertórios e identificavam os elementos contextuais durante a leitura, dava-lhes menos pistas, a fim de que pudessem ler com autonomia.

Os estudantes perceberam que há uma organização que antecede a escrita, que esta não é aleatória, que o autor é o primeiro leitor do texto e que este não pode fazer sentido 
apenas para quem o produz, haja vista seu propósito comunicativo. Assim, a observação das escolhas, linguísticas e semióticas, feitas pelos cartunistas lidos foi parte do processo para que, em atividade futura, se organizassem para criar suas próprias tiras, produzindo o roteiro, discutindo-o e elaborando, em equipe, a tarefa solicitada.

Adaptei as autoexplicações (ABARCA; RICO, 2003) para uma atividade de verificação da compreensão leitora, a fim de que pudesse observar a desenvoltura dos alunos sem minha intervenção. Com as autoexplicações, foi possível que os estudantes regulassem seu processo de leitura, elaborando suas próprias inferências a partir dos elementos linguísticos e semióticos constituintes das tiras. A análise das respostas dessa atividade mostrou que a leitura foi efetivada pela maioria dos alunos, entretanto alguns tiveram dificuldade de exteriorizar seu entendimento por conta dos problemas relacionados à elaboração da resposta escrita e à complexidade de organização do pensamento no papel.

Cabe destacar, ainda em relação a essa prática, o fato de nenhum dos sessenta e quatro estudantes terem deixado a atividade em branco, algo não observado na leitura de tiras em atividades anteriores. A isso, também, atribuí a não identificação, o que, talvez, tenha desobrigado o aluno da necessidade de acertar.

Tendo em vista a presença constante de tiras em livros didáticos, em provas diagnósticas, em jornais e revistas, dentre outros, é imprescindível que o estudante mobilize diferentes estratégias ao longo das aulas de Língua Portuguesa, a fim de que não se sinta intimidado diante da leitura de textos desse gênero. Cabe, então, ao professor, diante do gênero tira (e de qualquer gênero a ser trabalhado em sala de aula), motivar o aluno a ler, explicitar o objetivo da leitura, estimular a percepção das pistas textuais, visuais e verbais, conduzir à ativação de conhecimentos prévios, levar à construção de hipóteses e à elaboração de inferências, de modo que, gradualmente, os estudantes consigam realizar suas leituras com autonomia.

\section{REFERÊNCIAS}

ABARCA, Eduardo Vidal; RICO, Gabriel Martinês. Por que os textos são tão difíceis de compreender? As inferências são a resposta. In: TEBEROSKY, Ana et al. (Org.). Compreensão de leitura: a língua como procedimento. Porto Alegre: Artmed, 2003, p. 139-153.

BAKHTIN, Mikhail. Estética da criação verbal. Tradução de Paulo Bezerra. 6. ed. São Paulo: Martins Fontes, 2011.

GERALDI, João Wanderley (Org.). O texto na sala de aula. 5. ed. São Paulo: Ática, 2011.

GUEDES, Paulo Coimbra; SOUZA, Jane Mari de. Não apenas o texto mas o diálogo em língua escrita é o conteúdo da aula de português. In: NEVES, Iara Conceição Bittencourt et al. (Org.).

Ler e escrever compromisso de todas as áreas. Porto Alegre: UFRGS, 1999, p. 135-154. 
KOCH, Ingedore Villaça; ELIAS, Vanda Maria. Ler e escrever: estratégias de produção textual. São Paulo: Contexto, 2009.

KOCH, Ingedore Villaça; ELIAS, Vanda Maria. Ler e compreender: os sentidos do texto. 3. ed. São Paulo: Contexto, 2014.

MAINGUENEAU, Dominique. Análise de textos de comunicação. Tradução de Maria Cecília P. de Souza-e-Silva, Décio Rocha. 6. ed. São Paulo: Cortez, 2013.

RAMOS, Paulo. Histórias em quadrinhos: gêneros ou hipergênero? Estudos Linguísticos, São Paulo, 38 (3): 355-367, set.-dez. 2009.

RAMOS, Paulo. Tiras no ensino. São Paulo: Parábola, 2017.

SOLÉ, Isabel. Estratégias de leitura. 6. ed. Porto Alegre: Artes Médicas, 1998.

TRIPP, David. Pesquisa-ação: uma introdução metodológica. Educação e Pesquisa. São Paulo, v. 31, n. 3, p. 443-466, set./dez. 2005.

Recebido para publicação em: 5 maio 2020. Aceito para publicação em: 15 set. 2020. 